\title{
The Assessment of Speech Quality and Intellibility After Replacement of Lost Teeth With Removable Dentures: Review of Literature
}

\author{
Victoria Artjomenko*, Aldis Vidzis*, Kristine Broka** \\ *Riga Stradins University, Department of Prosthodontics, Riga, Latvia \\ ** Riga Stradins University, Department of Otorhinolaryngology, Riga, Latvia
}

\begin{abstract}
Summary
The prevalence of edentulism among Latvian population is high. According to the World Health Organization criteria complete tooth loss is regarded as a disability. One of the basic oral cavity functions is taking part in speech production. Alterations in oral cavity, caused by tooth loss and resorption of its supporting alveolar ridge, can produce changes in speech quality and intelligibility. This can lead to psychological and social problems, thus decreasing the patient's quality of life. There are several options in replacing missing teeth. In Latvia prosthetic rehabilitation with removable dentures is in great demand. It is mentioned in literature, that removable dentures improve speech quality and intelligibility. However, there is no consensus in this field. The objective of this review is to screen literature for data related to the assessment of speech quality and intelligibility after replacement of lost teeth with removable dentures. Literature was selected through several electronic databases, as well as a manual search in dental journals. The detailed analysis of thirty two articles was performed and some significant facts were revealed. There exists an opinion, that removable dentures may have a negative effect on speech production. As the volume of oral cavity is diminished, resonation of oral cavity is decreased. Artificial teeth, removable denture base can limit tongue space and change the location of its articulation contacts. The assessment of speech quality and intelligibility is an essential diagnostic tool before and after prosthetic rehabilitation in order to provide the best option for restoring lost function. A standardized method for determining changes in speech quality after tooth loss and further prosthodontics has not yet been established. Semi-standardized instruments for the analysis of speech disorders are well documented when dealing with speech changes before and after prosthetic rehabilitation with various oral osseointegrated implant supported prostheses. For the Latvian language this method has not been described yet.
\end{abstract}

Key words: tooth loss, edentulism, denture, speech quality and speech intelligibility

\section{INTRODUCTION}

The prevalence of edentulism among Latvian population is quite high $(19,40,41,42)$. Despite the fact that the average age of becoming edentulous is increasing, the total number of edentulous patients is declining less rapidly than could be expected $(7,33,40,42)$. This can be explained by increasing life expectancy. Therefore, $27.17 \%$ of Latvian inhabitants at the age of $35-44$ require prosthetic rehabilitation and at 65-74 years of age oral rehabilitation is needed for $60.4 \%(19,21,22)$. It is estimated (8) that the USA adult population in need of 1 or 2 complete dentures will increase from 33.6 million adults in 1991 to 37.9 million adults in 2020. According to World Health Organization (WHO) criteria (44) an individual who has lost all teeth, can be compared to a person who has lost a whole part of his body, and is considered to be physically impaired $(21,42,44)$. Tooth loss causes chronic disability; many edentulous patients have difficulty performing essential tasks such as eating, speaking and socializing. Teeth are important from the point of view of esthetics and their loss leads to the patient's dissatisfaction. Some patients may experience increased social and psychological problems $(22,40)$. One of the basic oral cavity functions is speech production $(9,12,45)$. Speech is an important form of verbal communication in society, which directly and indirectly affects person's quality of life $(5,7$, 12, 27). Its disorder can interfere with the daily and professional activities, especially in such professions as teachers, actors, singers, aviators (30). Rothman (32) states that normal speech production depends on proper functioning of five essential mechanisms: 1) motor, consisting of the lungs and associated musculature, 2) vibrator - vocal cords, 3) resonator, consisting of oral, nasal, pharyngeal cavities and paranasal sinuses, 4) initiator, consisting of the motor speech area of the brain and 5) articulators. Articulators can be divided into static or passive (teeth, hard palate, and alveolar ridge) and dynamic or active (tongue, lips, soft palate or velum) components $(4,35,45)$. Teeth and the above mentioned structures take part in performing the functions of oral cavity such as mastication and speech production. They play an important role in articulation of many speech sounds $(14,31,37,45)$. Alterations in oral cavity caused by tooth loss and resorption of alveolar ridge can produce changes in speech quality and intelligibility. In general, two main elements are influenced by these alterations the place of articulation of the tongue with hard palate and alveolar ridge mucosa changes $(12,28,35,37)$ and the resonator function of the oral cavity decreases (12, 
$22,27)$. Each language has its own phonetic system (25) that is why the assessment of speech quality and intelligibility after tooth loss and its replacement with removable dentures should be performed in the patient's native language $(25,45)$. This type of study has been made for German $(17,34,35)$, Czech (16), Italian (10), Turkish (27), Croatian (38) and Japanese (43) languages. In Latvian literary language there are 48 sounds (12 vowels, 10 diphthongs, 26 consonants) (25), as compared with 44 sounds in English (19 vowels, 25 consonants) $(30,45)$, the Czech language has 40 sounds (10 vowels, 3 diphthongs, 27 consonants) (16). When producing Latvian vowels the tongue and lips are performing their corresponding resonators $(5,32)$. Tooth loss and its consequences and further prosthetic rehabilitation do not usually influence vowel production (45). However consonants are usually affected (5, 9, 12, $31,35)$. Speech pathology uses the term "dyslalia" which means speech sound production disorders in the native language in conditions of normal hearing and speech organs innervation (25). Clinical cases analysis indicates $(9,10,12,14,28,31,34,35,37,45)$, that tooth loss and prosthetic rehabilitation with removable dentures most often affect sibilants (S, Z). In speech pathology this type of distorted pronunciation is called "sigmatism" $(25,12)$. Patients call this defect "lisping" $(10,32)$. More than $90 \%$ of Latvian consonants are produced by the tongue articulating with teeth, hard palate and anterior part of the alveolar ridge $(5,16,25)$. Physiologically consonants are characterized as sounds or noises which occur when the exhaled air flow overcomes the obstacle $(5,25)$. Depending on air flow obstruction place the Latvian language consonants are divided into bilabial $(\mathrm{p}, \mathrm{b}, \mathrm{m})$, labiodental (f, v), dental $(\mathrm{t}, \mathrm{d}, \mathrm{s}, \mathrm{z}, \mathrm{c}, \mathrm{dz}, \mathrm{n})$,

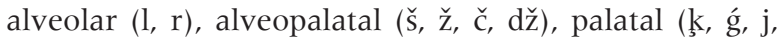
n, l $)$, velar consonants $(\mathrm{k}, \mathrm{g})$ and pharyngeal $(\mathrm{h})(5$, 12). The aim of oral prosthetic rehabilitation $(45,46)$ is to restore oral cavity functions - food milling, speech, comfort and esthetics, thus improving the patient's quality of life and self- esteem (14, 31, 42, 45, 46, 39). In case of extensive or complete tooth loss, it is possible to fabricate acrylic removable dentures, supported by soft tissues. Such constructions are known to have several shortcomings - they cover a large part of prosthetic field, their functional value depends on oral anatomy and they are removable $(13,28,45)$. It is assumed that food milling capability with removable dentures is restored to $25 \%$ of the total masticatory effectiveness (33). The restoration of oral function plays an important role in patient's satisfaction with removable dentures and oral rehabilitation acceptance $(7,33,37,38,46)$. Despite all limitation, the degree of patient satisfaction with removable partial and total dentures is high $(7,33)$. In Latvia this type of restoration of tooth loss and its supporting alveolar bone is in great demand $(19,40,41$, 42).

\section{The influence of removable denture on speech quality and intelligibility}

It is mentioned in literature $(13,14,17,28,38,39)$, that removable dentures improve speech quality and intelligibility. However there's no consensus in this field. It is considered $(9,10,13,28,31,38,45)$, that removable dentures may have a negative effect on speech production, as the volume of oral cavity is diminished. Artificial teeth, removable denture base can limit space for the tongue and change location of its articulation contacts with hard palate and alveolar ridge mucosa $(5,24,28)$. Nowadays, a number of methods are available for speech assessment. Some of them are more useful for speech changes analysis in case of tooth and supporting structure loss and after prosthetic rehabilitation with removable dentures $(16,17,28,31$, $34,35,37,45)$. A standardized method for determining speech quality changes after tooth loss and further prosthodontics has not yet been established $(17,23,37)$. Semi-standardized instruments for the analysis of speech disorders are well documented when dealing with speech changes before and after prosthetic rehabilitation with various oral osseointegrated implant supported prostheses $(24,23)$. Two facets of speech perception are described in literature - speech intelligibility $(17,31,37)$ and speech quality $(16,28,34,35)$. Both of them are multidimensional terms. Speech intelligibility is defined as ability of a native educated listener to perceive oral speech, understand it, and distinguish separate sentences, words, and letters $(37,39)$. One of the most popular analyses of speech quality and intelligibility is evaluation done by speech pathology $(12,27,31)$. For more reliable results several experts' evaluation is required. In order to perform speech analysis direct speech samples or audio or video records, made in accordance with standardized speech pathologist tests, can be used $(16,24,31)$. Rodrigues published analysis of speech in different oral prosthetic rehabilitation modalities for elderly individuals. Video speech samples of 36 patients were analyzed by five speech-language pathologists. It was concluded that individuals using removable dentures present alteration in linguodental and alveolar phonemes. The type of prosthesis and its stability do not seem to interfere with speech production (31). Hassel proposed an easy method for improving speech function of complete maxillary denture (two speech therapists participated in this research) (10). In his turn, Ozbek evaluated the articulation of Turkish phonemes after removable denture application, 3 speech pathologists investigated the speech records of 15 patients before and after removable denture insertion and after a week of adaptation. The results showed that for some phonemes, problems in articulation occurred after the insertion of a removable partial denture while for others a significant amelioration was observed. In general, problems in articulation of evaluated phonemes were resolved after one week of adaptation (11). The speech pathologist's analysis is considered to be "golden standard" in case of prosthetic rehabilitation (12, 17, 37). However, this method has some drawbacks, as its objectivity depends on the expert's experience, acute of hearing and, perhaps, psychological perception (37). It is essentially a subjective expert investigation method, 
so researchers are looking for more objective methods of speech changes qualitative analysis. A group of German specialists introduced and validated a computer-based speech recognition system for the standardized and automatic speech assessment in edentulous patients after dental rehabilitation with complete removable denture $(17,37)$. With the help of this system the speech intelligibility and word accuracy (WA) can be measured. Stelzle (37) applied this system to the analysis of speech changes after tooth loss and prosthetic rehabilitation with removable dentures in 28 patients. The author came to the conclusion that the system can be used for speech intelligibility evaluation and also confirmed the fact that complete loss of teeth can cause a dramatic deterioration of speech and removable complete dentures do not fully solve the problem. In 2011 using the same system Knipfer (17) analyzed 45 patients and found that removable dentures improve speech intelligibility - after six month of adaptation the quality of speech in control group and the experimental group was equal. Speech quality is associated with the sound volume, intensity, intonation, timbre, sound pronunciation accuracy and physical spectral characteristics $(28,34,35)$. The spectral analysis is widely used for quality of speech evaluation $(16,28,34,35)$. It is an independent diagnostic tool for the assessment of speech quality regarding alteration of the dental arch. This is an objective, accurate and reliable method of sound analysis, but it can be used to investigate only certain sound parameters and it is not possible to make evaluation of the overall speech quality changes $(17,37)$. With the help of spectral analysis the acoustic characteristic of speech sound can be determined. There are dynamic and static spectrograms. For speech quality changes evaluation the static spectrogram, namely one obtained by a computer program fast Fourier transformation (FFT) power spectrum, is used more frequently $(11,12,16,35)$. The speech sound is analyzed in three dimensions: frequency, amplitude and chronologic sequence. The " $\mathrm{S}$ " sound pronunciation is most often used for spectral analysis $(10,34,35)$. Its formation mechanism is complicated $(12,29,34,35)$. In spite of considerable interlanguage phonetic diversity, "S" sound pronunciation mechanism is similar in most languages $(34,45)$.

\section{The arrangement of artificial teeth and speech sounds production mechanism}

Spectral analysis is usually used to measure the influence of the maxillary central incisors on speech quality changes before and after prosthetic treatment $(28,34,35)$. Stojevci (38) analyzed the formation mechanisms of Croatian dental and postalveolar group of sounds and removable denture impact on the sound pronunciation accuracy. The results showed that subjects with partial removable denture had $50 \%$ less distortion variables and that prostheses did not completely restore articulation of postalveolar sounds. Groups with and without removable dentures had lower formant peaks intensity and wider formant bandwidths as compared with the control group. Partial removable dentures have not significantly interfered with resonance frequency. At the same time, pronunciation of the examined sounds was significantly improved; however, precision of the articulation movements has deteriorated (38). Using the spectral analysis method Runte indicates that the maxillary incisors play an important role in the " $\mathrm{S}$ " sound production and even minimal displacement of the teeth, causes the sound production distortion. The labial angulation seemed to have a greater effect than the palatal displacement $(34,35)$. It was also concluded that neuromuscular reactions are more important for initial speech sound distortions than are aerodynamic changes in the anterior speech sound - producing area $(34,35,45)$. That is why artificial teeth should be placed in the original position of the lost natural teeth $(10,34$, 35). For artificial teeth arrangement it is recommended to use anatomical landmarks (papilla incisiva and first prominent rugae palatinae), these will ensure the artificial teeth arrangement in agreement with phonetic and esthetic requirements $(35,45)$. In production of sibilant sound "S" lower jaw protrudes and takes the position that corresponds to the "closest speaking space" (CSS), which means that 1-2 mm gap is formed between upper and lower incisors $(29,32)$. It is assumed that the distance is constant and doesn't change during lifetime; however there is no confirmation of this fact (it is stated in literature, that parameters vary from 0 to $10 \mathrm{~mm})(6,36)$. In the process of production of "S" sound the lateral surface of the tongue occludes with the upper premolars and its supporting alveolar ridge, the exhaled air flow is pushed between the front teeth and thus characteristic noise is formed $(29,30)$. An essential factor in the production of correct " $\mathrm{S}$ " is the proper grooving of the tongue $(9,29,32)$. In case this groove is too shallow, "S" sound is softened and becomes similar to "Sh" sound, that's why if the removable dentures base is thicker in the anterior part the lisp distortion occurs $(9,18,32,33)$. If this groove is formed too deeply, the patient will whistle and then it is recommended to make the removable dentures base thicker $(9,18,32)$. "S" sounds production can be distorted as a result of air leakage, when the tongue is not sufficiently supported in the bicuspid region $(1,32)$. In addition to spectral analysis, it is possible to use palatogram $(4,35)$. This method is suitable for identification of the exact contact of the tongue with hard palate. The palatogram is made by covering the palatal surface of existing denture with colorant. Then during pronunciation of the tested phonemes the exact places of the tongue and denture base contact can be seen. Several methods of palatography are described in literature $(3,4,9,18)$, but the purpose is the same - to personalize removable denture base to patient's physiology, so that quicker phonetic adaptation can be achieved $(9,18,29,32)$. In order to check and verify the artificial anterior incisor position and length it is proposed to use " $\mathrm{F}$ " and " $\mathrm{V}$ " phonemes tests. When producing these sounds the upper incisors are touching the lower lip at the Vermillion border or dry-wet line (45). If teeth are too short, " $\mathrm{V}$ " will sound as " $\mathrm{F}$ " and if 
teeth are too long "F" will sound as "V" $(12,32,33,45)$. Removable denture base and speech sounds production

In removable denture the base is an essential part of the construction $(5,27,28,45)$. It provides retention, support and stability and at the same time it can cause significant phonetic distortions $(9,13,18,28)$. In case of complete removable denture its margins have to be maximal in order to provide its functionality $(30,32$, $45)$. If margins are too short, the functional value of the construction will be decreased, on the other hand if margins are too long bilabial sounds $(\mathrm{p}, \mathrm{b}, \mathrm{m})$ will be distorted, because the lips will not occlude properly (30, $32,45)$. The distal margin of removable denture plays a significant role - a properly placed distal margin has to cover fovea palatine and to be situated on " $\mathrm{A}$ " line. It is recommended to use " $\mathrm{A}$ " sound phonetic test $(30,32)$. Correctly placed distal margin will decrease the air flow under the denture, which will improve the functional value of the denture and will minimize phonetic abnormality $(2,30,32)$. When planning removable partial denture design, it is advisable to avoid covering of hard palate in anterior part, as in $90 \%$ of consonants production the tongue articulates with this region (9, $12,32)$. While modeling the removable denture base it is essential to preserve hard palate configuration and avoid unnecessary reduction of oral cavity volume $(9,18,28)$. The denture has to be well adapted to the oral cavity peculiar anatomy features (28). Denture base should be as thin as possible in order to minimize alteration of oral cavity resonance $(5,28,29)$, as well as to minimize the distortion of tongue movement during speech sound production. At the same time the removable denture should be thick enough to withstand its deformation under masticatory forces (45). It is considered that (5, $13,28)$ the optimal thickness of the denture base should be 1.4-2 mm thick. Rugae reproduction on removable dentures base is a subject of significant controversies $(28,32)$. On the one hand it will make denture base thicker, on the other hand there are certain sounds, namely palatolingual "T", „D”, „N", and „L" for whose production tongue orientation elements are needed $(12,32)$. In case of metal removable denture the major connection is made by using corrugated surface, therefore reducing the "foreign body sensation" and providing faster phonetic adaptation $(9,10,28)$.

\section{Phonetic adaptation of patients with removable denture}

The phonetic adaptation of a patient with removable dentures depends on: the patient's individual adaptation capacity $(16,27,29,34,45)$, his sound recognition capacity, sharpness of hearing $(24,45)$, functional value of the dentures $(5,14,24,45)$, artificial teeth selection and arrangement $(16,29,34,35,45)$, removable dentures base design and thickness $(4,16,43,45)$. Speech is an acquired complex process $(27,45)$. After removable denture insertion the oral cavities volumetric parameter alters and as a result transitory speech distortion occurs $(16,17,28,45)$. According to the research data phonetic adaptation to the removable partial denture lasts from 2 to 4 weeks $(28,31,45)$. As for senior patients their individual adaptation capacity decreases, and speech function restoration may take longer time, which is usually connected with deterioration of hearing and overall aging process $(13,45)$. It is recommended to warn the patients before insertion of new dentures about the possible speech problems and to provide information on the possibility of improving of speech quality by doing some exercises and practicing difficult phonemes $(45)$. It is generally recognized $(27,35,45)$ that artificial teeth in dentures should be placed in lost teeth places, in order to match the patient's existing neuromuscular pattern. It will ensure faster phonetic adaptation because in this case fewer adjustments in patient's neuromuscular pattern are needed. The less difference there is between the form, position, palate topography, configuration and anatomy of the lost teeth and the restored artificial ones, the quicker and easier the phonetic function will be restored (the theory of "less effort") (45). If changes in oral cavity are great and are beyond the patient's individual adaptation capacity, persistent speech disorder will occur $(22,38,45)$.

\section{The functional value of removable dentures} (support, retention, stability)

As well as all factors mentioned above, the functional value of removable dentures plays an important role in speech production $(22,39,45)$. The tongue of patient wearing denture has an additional function of stabilizing and retaining the denture. With diminishing functional value of the prosthesis, more of additional function of the tongue is required; it may have negative impact on speech quality $(22,30,39)$. The functional value of removable dentures depends on the precision of its production. Inaccurate fabrication of denture will produce a defective prosthesis, which doesn't correspond to the prosthetic field and thus its functional value is decreased $(30,39,45)$. Even if after insertion of removable dentures they match the functional requirement, after some period of exploitation there functional value can be reduced $(39,45)$. The denture can become loose and disturbing to the patient. This can be caused by alveolar bone resorption, which is a physiological process after tooth extraction (15, $20,22)$. The process is especially rapid in the course of the first year after tooth extraction; as a result the volume of alveolar bone decreases and its morphology changes. The total supporting surface is reduced forming an unfavorable prosthetic field $(15,20,22)$. Recently much attention has been paid to atraumatic tooth extraction and effective bone and soft tissues preservation procedure $(15,20)$. The method of tooth extraction influences the degree of consequent bone resorption. Further prosthetic rehabilitation success, both functional and esthetic, depends on preservation of the remaining structure morphology and quantity $(15,30,45)$. Several methods $(15,20)$ for alveolar ridge preservation after tooth extraction have been reviewed in literature; however, due to diversity of research design it is impossible to conclude which is the 
most effective one. Thus the problem of soft and hard tissues preservation after tooth extraction remains so far unresolved. After tooth extraction and immediate prosthetic treatment the patient should be informed of the necessity of further corrections, relining and controlling of removable denture (45).

\section{CONCLUSIONS}

Analysis of the data found in current dental literature has made it possible come to the following conclusions:

- Alterations in oral cavity caused by tooth loss and resorption of alveolar ridge can produce changes in speech quality and intelligibility.

- Rationally planned and designed removable denture, made according to phonetic needs, improves patient's speech function.

- Removable dentures functional value is an important factor for restoration of the lost function, including speech.

- The degree of resorption of the bone is one of decisive factors for successful outcome of oral rehabilitation. Tooth extraction methods and techniques partially influence the degree of further bone resorption.

\section{Conflict of interest: None}

\section{REFERENCES}

1. Arora S. Phonetics - its role in prosthodontics // India J of Dental Science, 2011 ; 3:36-40

2. Balu K, Karthik. Speech in prosthodontics Type of literature: commentary // JIADS, 2011 ; 2(2): 79-81

3. Bhawsar S. Reproducing functional palatal contours in complete dentures to improve speech - a case report // JIDA, 2012; 6:111-114

4. Bortun C, Leretter M, Sandu L, et al. Phonetic evaluation of the edentulous patient correlated with the various settings of the artificial teeth // Serbian Dental J, 2004; 5:93-96

5. Broka K, Sokolovs J, Vidžis A. Balss kvalitātes ietekmējošie faktori un to uzlabošanas iespējas // RSU Zinātniskie raksti, 2011; 159-166

6. Burnett CA, Clifford TJ. Closest speaking space during the production of sibilant sounds and its value in establishing the vertical dimension of occlusion // J Dent Res, 1993; 72(6):964-967

7. Dierens M, Collaert B, Deschepper E, et al. Patientcentered outcome of immediately loaded implants in the rehabilitation of full edentulous jaws // Clin Oral Impl Res, 2009; 20:1070-1077

8. Douglass CW, Shih A, Ostry L. Will there be a need for complete dentures in the United States in 2020? // J Prosthet Dent, 2002; 87:5-8

9. Farley DW, Jones JD, Cronin RJ. Palatogram assessment of maxillary complete dentures // J of Prosthodontics, 1998; 7(2):84-90

10. Giovannetti M. Phonetics analysis of maxillary anterior tooth position : a pilot study on preliminary outcomes // International Dentistry, 2010; 11:1-6
11. Hamlet SL, Stone M. Speech adaptation to dental prostheses: the former lisper // J Prosthet Dent, 1982; 47(5):564-569

12. Hassel JA, Holste T. Improving the speech function of maxillary complete dentures: a pilot study // Int J Prosthodont, 2006; 19:499-503

13. Ichiwaka J. Influence of alteration in the oral environment on speech production // J Oral Rehabil, 1995; 22:295-299

14. Inukai S, Hideshima M, Sato M, et al. Analysis of the relationship between the incisal overjet in a maxillary denture and phonetic function using a speech recognition system // Prosthodont Res Pract, 2006; 5:171-177

15. Irinakis T. Rationale for Socket Preservation after Extraction of a Single-Rooted Tooth when Planning for Future Implant Placement // J Can Dent Assoc, 2006; 72(10):917-922

16. Jindra $P$, Eber $M$, Pešak J. The spectral analysis of syllables in patients using dentures // Biomed Papers, 2002; 146(2):91-94

17. Knifer C, Bocklet T, Noeth E, et al. Speech intelligibility enhancement through maxillary dental rehabilitation with telescopic prostheses and complete dentures: A prospective study using automatic, computes-based speech analysis// Int J Prosthodont, 2012; 25:4-32

18. Kong H. Customizing palatal contours of a denture to improve speech intelligibility// J Prosthet Dent, 2008; 99:243-248

19. Krasta I, Vidzis A, Brinkmane A. et al. Evaluation of oral therapeutical and surgical treatment needs among retirement age population in different countries // Acta Chirurgica Latviensis, 2011;11/2:139-143

20. Kubilius M, Kubilius R, Gleiznys A. The preservation of alveolar bone ridge during tooth extraction // Stomatologija, Baltic Dental and Maxillofacial Journal, 2012; 14(1):3-11

21. Laurina L, Soboleva U, Treimane L. Bezzobu žoklu protezēšanas izvērtējums Latvijas vispārējās zobārstniecības uzņēmumos // RSU Zinātniskie raksti, 2006; 361-364

22. Laurina L., Soboleva U., Construction faults associated with complete denture wearers' complains// Stomatologija, Baltic Dental and Maxillofacial Journal, 2006; 8(2); 61-64

23. Lierde KM, Corthals $\mathrm{P}$, Browaeys $\mathrm{H}$, et al. Impact of anterior single-tooth implant on quality of life, articulation and oromyofunctional behavior: a pilot study // J of Oral Rehabil, 2011; 38:170-175

24. Lundqvist S, Lohmander-Agerskov A, Haraldson T. Speech before and after treatment with bridges on osseointegrated implants in the edentulous upper jaw // Clin Oral Impl Res, 1992; 3:57-62

25. Miltiņa I., Skaņu izrunas traucējumi. Rīga: Raka, 2005

26. Osterberg T, Carlsson GE, Sundh V. Trends and prognoses of dental status in the Swedish 
population: analysis based on interviews in 1975 to 1997 by Statistic Sweden // Acta Odontologica Scandinavia, 2000; 58: 177-182

27. Ozbek M, Tuluno-Lu B, Ozkan S, et al. Evaluation of articulation of Turkish phonemes after removable partial denture application // Braz Dent J, 2003; 14(2):125-31

28. Petrovic A., Speech sound distortions caused by changes in complete denture morphology// J Oral Rehabil, 1985; 12: 69-79

29. Pound E., Utilizing speech to simplify a personalized denture service // J Prosthet Dent, 2006; 95:1-9

30. Ravishankar K., Phonetics and flight safety-an orodental view point// Ind J Aerospace Med, 2002; 46(2): 54- 58

31. Rodrigues LCB, Pegoraro LF, Brasolotto AG, et al. Speech in different oral prosthetic rehabilitation modalities for elderly individuals // Pro-Fono Revista de Atualizacao Cientifica, 2010; 22(2):151156

32. Rothman R. Phonetic Considerations in denture prosthesis // J Prosthet Dent, 1961; 1 1:214-223

33. Roumanas ED. The social solution - denture esthetics, phonetics and function // J of Prosthodontics, 2009; 18: 112-115

34. Runte C, Lawerino $M$, Dirksen D, et al. The influence of maxillary central incisor position in complete dentures on /s/ sound production // J Prosthet Dent, 2001; 85:485-495

35. Runte C, Tawana D, Dirksen D, et al. Spectral analysis of /s/ sound with changing angulation of the maxillary central incisors // Int J Prosthodont, $2002 ; 15: 254-258$

36. Souza RF, Compagnoni MA. Relation between speaking space of the /s/ sound and freeway space in dentate and edentate subjects // Braz Oral Res, 2004; 18(4):333-337

37. Stelzle F, Ugrinovic B, Knipfer C, et al. Automatic, computer- based speech assessment on edentulous patients with and without complete denturespreliminary results. J of Oral Rehabil, 2010; 37: 209-216

38. Stojčevic I, Carek A, Bukovic D, et al. Partial Denture and sounds// Coll antropol, 2004; 28(2):799-807
39. Teodorescu H-N.L Voice analysis in dentistry // J of Romanian Medical Dentistry, 2010; 14(3):171-186

40. Vidzis A, Cema I, Brinkmane A, et al. Quantity and quality analysis of dental prosthodontics among retirement age residents from nursing homes in different regions of Latvia and retirement age patients from dental clinic in Riga // Stomatologija, Baltic Dental and Maxillofacial Journal, 2012; 14:23-27

41. Vidzis A, Cema I, Krasta I, et al. Evaluation of oral healthstatus of retirement-agepopulationinLatvia // Stomatologija, Baltic Dental and Maxillofacial Journal, 2011; 13:68-72

42. Vidzis A, Cema I, Krasta I, et al. Evaluation of Oral Health Status and the Need of Surgical and Therapeutical Preprosthodontic measures in the Elderly Living in Old People`s Homes in Latvia // Acta Chirurgica Latviensis, 2009; 9:67-70

43. Wada J. Influence of the major connector in a maxillary denture on phonetic function // J of Prosthodontic Res, 2011; 55:234-242

44. World Health Organization. International classification of functioning, disability and health.ICF Geneva: World Health Organization, 2001

45. Zarb GA, Karlsson SL. Speech considerations with complete dentures // In: Zarb GA, Bolender L. Prosthodontics treatment for edentulous patients. 12st ed. St. Mosby; 2004; 379-397

46. Zlataric D. Factors related to patients general satisfaction with removable partial dentures: a stepwise multiple regression analysis // Int $\mathrm{J}$ Prosthodont, 2008; 21:86-88

\section{Address:}

Viktorija Artjomenko

Riga Stradins University, Department of Prosthodontics 20 Dzirciema Street

Riga, Latvia, LV-1007

E-mail: baravik@inbox.lv 